\title{
Pacing after acute myocardial infarction
}

\author{
Alan Harris \\ B.Sc., M.D., M.R.C.P. \\ Cardiac Department, St George's Hospital, London, S.W.1.
}

\begin{abstract}
Summary
Experience of endocardial pacing in eighty-two patients with atrioventricular block after myocardial infarction is described. A unipolar pacing wire was passed into an antecubital fossa vein and passed into the right atrium and wedged into the apex of the right ventricle under radiological control using an image intensifier. All patients were attached to an external demand unit set at $60 / \mathrm{min}$ which will pace if there is asystole longer than 1 sec. The disadvantages of pacing are discussed.
\end{abstract}

$A$ fall in mortality occurred from $71 \%$ of unpaced patients to $38 \%$ of thirty-seven patients where demand pacing was given. When suppressant drugs (lignocaine, procainamide and quinidine) were given in addition to pacing the mortality dropped to $11 \%$ of twentyseven patients. The disadvantages of pacing are few and it is considered that suppressant drugs are only used with safety when a pacing system has been installed.

AcuTE myocardial infarction is complicated by complete heart block in $5-8 \%$ of all patients (Brown, Hunt \& Sloman, 1969) and when untreated carries a mortality rate ranging between $48-71 \%$ Transvenous endocardial pacing for the management of Adams-Stokes disease is now established as a satisfactory method of treatment. More recently temporary transvenous pacing has been successfully used for the treatment of the acute disturbances of atrio-ventricular conduction which may follow acute myocardial infarction (Epstein et al., 1966; Harris \& Bluestone, 1966; Lassers \& Julian, 1968). During the past 9 years we have treated ninety-five patients with second degree or complete atrioventricular block complicating acute myocardial infarction. The majority of these patients have been referred to our unit from other hospitals and hence there must be some element of selection which might have influenced our results. Details of the first fifty-five patients and the technique used have been reported (Sutton, Chatterjee \& Leatham, 1968).

\section{Method}

We prefer to use a US Catheter Corporation uni- polar C 5650 or bipolar C 5651 transvenous wir passed via a medially placed antecubital fossa veiळ exposed under local anaesthesia. There are some whos advocate the percutaneous subclavian vein approact but this technique requires a high degree of skill te avoid local complications such as pneumothorax of damage to the brachial plexus. We prefer not to us the external jugular veins for temporary pacing bitit to preserve these in case long-term pacing is eventlb ally required. The transvenous wire is passed into the right atrium using a high-definition image intensifier The bipolar electrode wire avoids the need for separate positive electrode but is slightly more rigin than the unipolar wire. The electrode wire is passed through the tricuspid valve, usually by making a logop off the right atrial wall, and then into the pulmopary artery, thereby demonstrating that the electrode has not been inadvertently placed in the coronar sinus. The electrode is then withdrawn from the pulmonary artery and its tip manoeuvred into position as low down and as far out in the apex बㅇ the right ventricle as possible (Fig. 1) and 'wedged into position by gentle pressure. Sometimes man? positions at the apex of the right ventricle have to be tried before a stable site is found. During the manipulation of the electrode tip within the right ventricle, ectopic rhythms may be induced but the usually disappear once pacing is started. The wire is attached to an external demand pacing box (Device Implants Ltd.) and the threshold for pacing (voltage required) is measured and this should be less tha 1 volt at $2 \mathrm{sec}$ duration. Pacing is then commenced at just above the measured threshold and the stability of the electrode tip in the right ventricle is checked by encouraging the patient to breathe deeply, and $\overline{\mathrm{O}}$ cough; if these actions interrupt pacing even for on cycle, another position is found. If the electrode wire is 'wedged' with unnecessary force then perforation of the myocardium will occur (Fig. 2) leading to early or late loss of pacing, but rarely causing tamponade.

A further test of satisfactory electrode tip impae? tion is obtained by recording the endocardial electroo cardium, by attaching all four limb leads of $\vec{Q}$ battery-powered electrocardiograph to the patien 


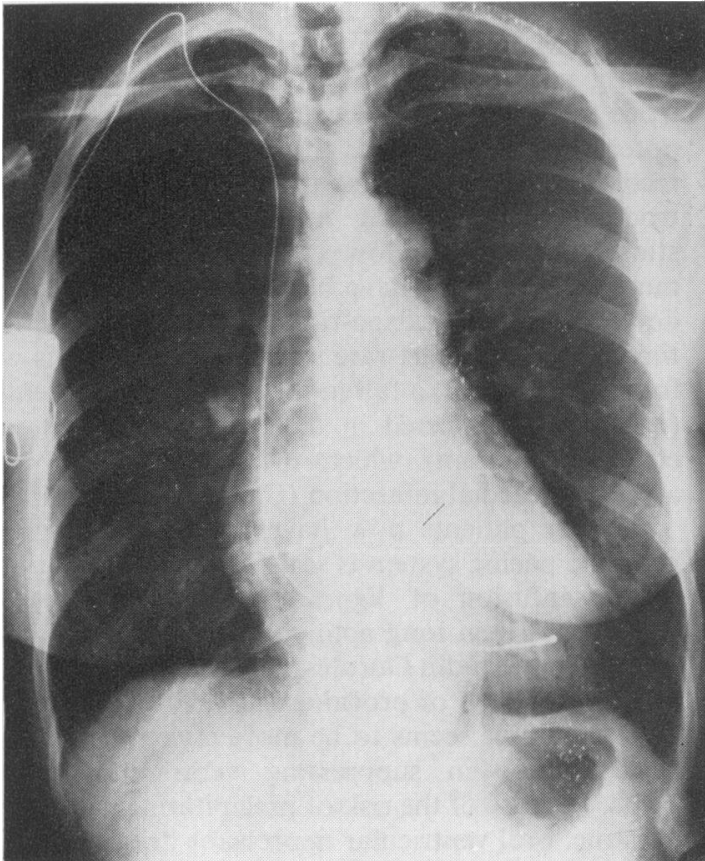

FIG. 1. Chest X-ray showing a satisfactory endocardial electrode position. The electrode tip is 'wedged' at the apex of the right ventricle. The course of the wire through the right atrium is free from redundant loops.

and the chest lead switched to $V_{1}$ connected to the free end of the endocardial electrode wire. When the endocardial electrode is well impacted into the right ventricular wall an injury pattern with elevation of the S-T segment of at least $2-3 \mathrm{mV}$ is usually obtained (Fig. 3). The patient should then be screened again to observe that no redundant wire has been left in the right atrium (Fig. 4) since later a loop may

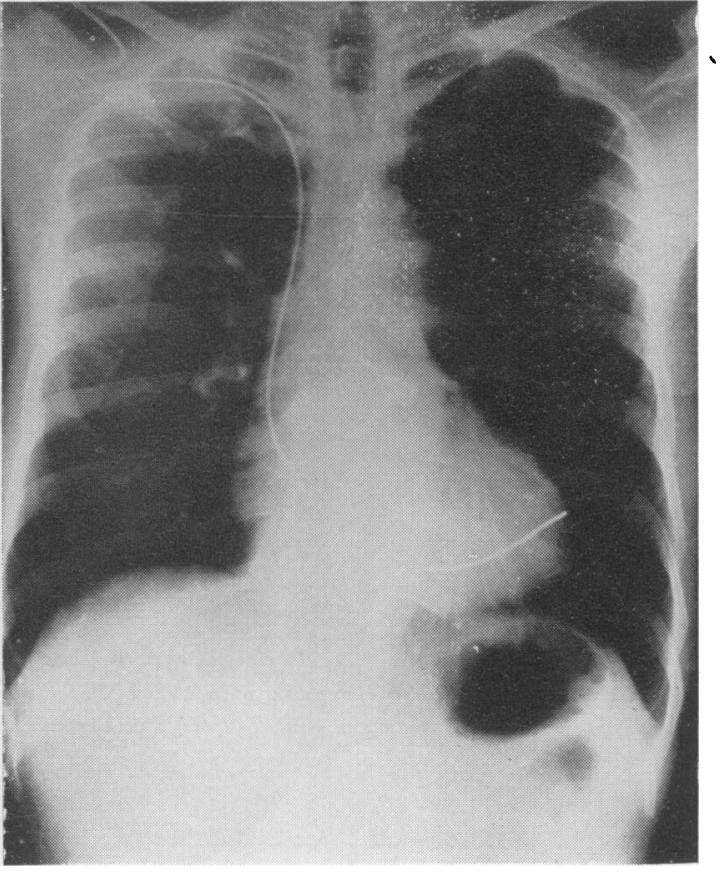

FIG. 2. Chest X-ray showing myocardial perforation by the electrode tip which is lying beneath the pericardium.

form in the electrode wire within the heart resulting in the withdrawal of the electrode tip from a stable position and intermittent pacing may result.

Once an ideal pacing position is obtained the electrode wire is firmly tied to the antecubutal fossa vein and neighbouring tissues with several silk sutures. If a unipolar wire has been used then an indifferent electrode will have to be placed in the

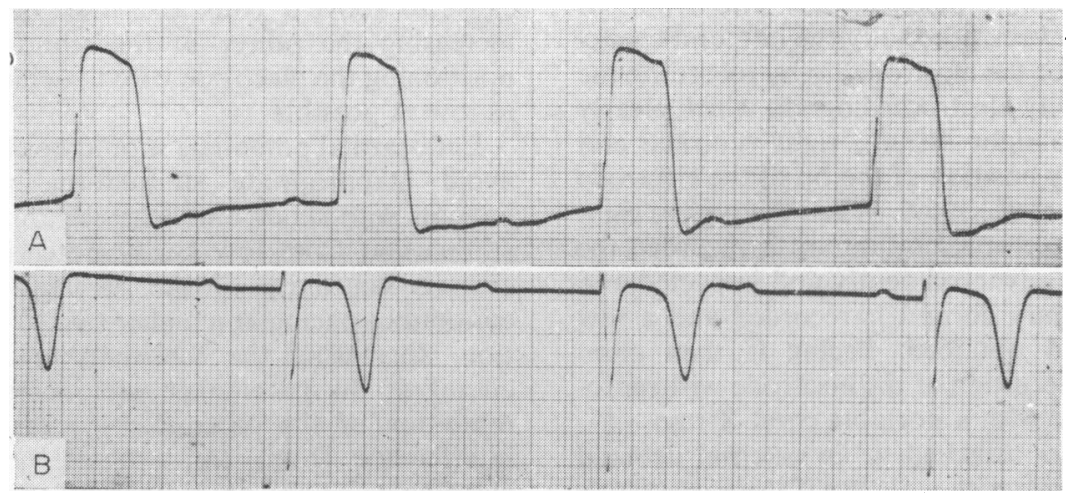

FIG. 3. Endocardial electrocardiogram showing in (A) a good injury potential indicating the electrode tip is satisfactorily 'wedged' and in (B) a poor injury potential indicating the electrode tip is not in satisf ctory contact with the endocardium. 


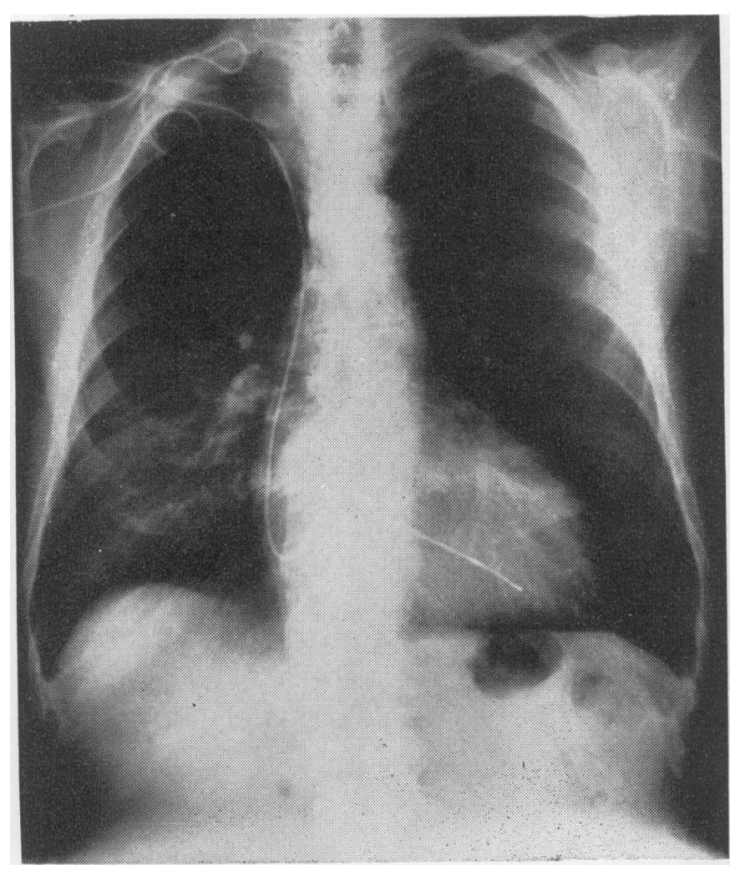

FIG. 4. Chest X-ray showing a redundant loop of electrode wire in the right atrium which later resulted in loss of pacing.

subcutaneous tissue and similarly fixed. The main disadvantage with the use of an arm vein is the ease of displacement of the electrode tip from the 'wedged' position if unrestricted arm movement is permitted. We therefore always restrict arm movement with a special harness but satisfactory restriction can be obtained with a fracture board.

Occasionally the situation may demand that transvenous pacing be carried out without X-ray screening facilities. This may be quite rapidly achieved by passing the electrode wire from an antecubital fossa vein, especially the left, and checking the position of the electrode tip by recording the intra-cardiac cavity electrocardiogram which clearly differentiates the right atrium, right ventricle and pulmonary artery position of the tip of the electrode wire (Chatterjee et al., 1969). When the typical right ventricular cavity electrocardiogram is recorded the electrode wire is advanced gently and impacted and often a good injury current is recorded and a low pacing threshold obtained. Pacing is then commenced and the position of the electrode wire radiologically checked with a portable chest X-ray.

All patients are attached to an external demand unit set at $60 / \mathrm{min}$, which will pace if there is asystole longer than $1 \mathrm{sec}$, at no more than twice the minimum voltage required to stimulate the right ventricle. Demand pacing with low power will theoretically lower the risks of inducing ventricular fibrillation by inappropriate stimulation during ectopic rhythms oro during sinus competition ( $R$ on $T$ ). A unipolar elec- $C$ trode is recommended because a greater intracardiac potential (which inhibits the demand pacemaker) is recorded with a unipolar than with a bipolar elec- $\frac{\mathrm{C}}{\mathrm{C}}$ trode thereby reducing the risk of inappropriate stimulation due to low intracardial potential. $A_{\overparen{D}}^{-}$ number of patients have been observed to suddenly develop competing fixed-rate pacing although at thes time their own heart rate was satisfactory; this was found to be due to a fall in the intracardiac potential(not usually reflected in the conventional externatw electrocardiogram) which often occurs following acute myocardial infarction (Chatterjee et al., 1970)윽

All our patients now have suppressant therapy. once the pacing system is satisfactory, usually intravenous infusion of lignocaine $(1-3 \mathrm{mg} / \mathrm{min})$ for 3 days and then long acting quinidine as quinidine bisulphate (Kinidin Durules, Astra Chemicals) 0.25 go four times daily, or procainamide $250-500 \mathrm{mg}$ q.d.s은 Oral quinidine seems to be more effective than oralprocainamide in suppressing ventricular ectopic beats. Because of the risk of precipitating ventricular asystole, oral ventricular depressant drugs must not be started until the pacing system is installed Continuing ectopic beats despite increased dose go suppressant therapy are treated by increasing thepacing rate, but care must be taken when ventricutâtir function is borderline since too fast a rate mâs induce heart failure.

Heart failure is treated by diuretics and digitalis and lack of improvement with atrio-ventriculas pacing (requiring a second transvenous wire to pace the atrium) in order to obtain the benefit of atria! transport.

The threshold of stimulation is checked daily, and pacing voltage should be set at not more than twice the threshold value. A rise of threshold from any cause to above 2 volts at $2 \mathrm{msec}$ is not treated by் increasing the power of the stimulus but by re 3 . positioning the electrode wire to achieve a threshold as low as possible.

Endocardial potentials should be checked daily tø avoid inappropriate stimulation, particularly in patients with shock and heart failure. Inappropriate stimulation from low cavity potential requires in creased sensitivity of the demand pacemaker of continuous pacing at a higher rate to avoid competio tion. Increasing the sensitivity of the inhibiting circuit of the pacemaker will increase the risk of inhibition of the pacemaker by external electrical interference from, for example, electric razors cleaning machines, physiotherapy appliances or evef? by potentials from skeletal muscle activity (Fig. 5). The demand system is left in position for 1 weelo after return to sinus rhythm (average 2 days) and 


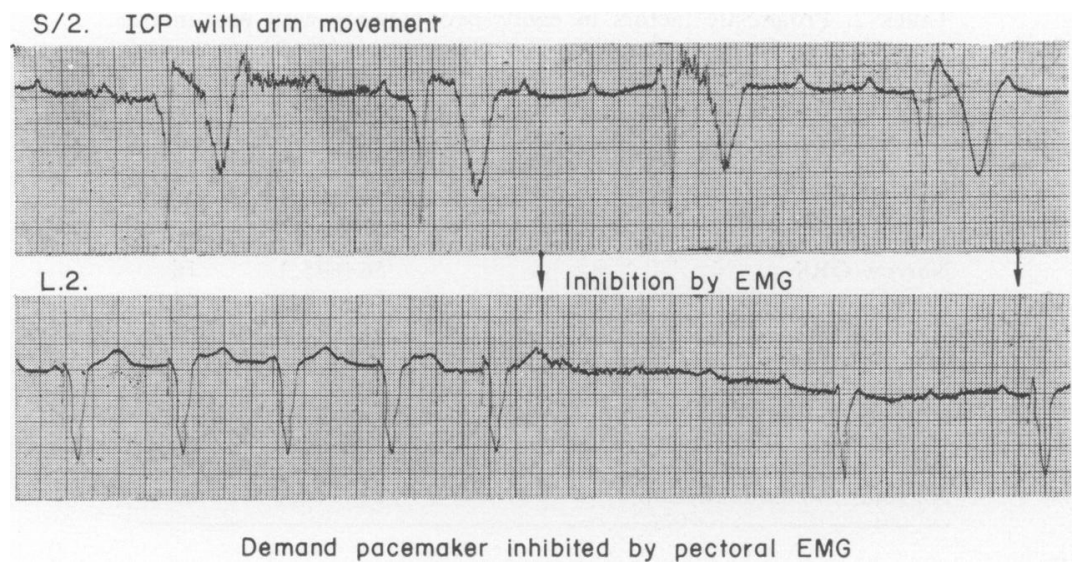

FIG. 5. The effect of the pectoral muscle electromyogram (EMG), during arm movement, on the endocardial electrocardiogram (ICP) in an unpaced subject (unipolar system). Demand pacing with a sensitive box is interrupted by the pectoral EMG.

P. J. Reynolds pace beat counter is connected with an external demand pacemaker (set at 50) for the final $24 \mathrm{hr}$ to exclude intermittent block, which requires prolongation of pacing care. If the pace-counter shows no pacemaker action for $24 \mathrm{hr}$, the pacing system is removed but suppressant drugs are continued.

\section{Results}

The first eighty-two patients were divided into three groups according to the date of treatment and the technique (Table 1). The thirty-two patients who were unpaced (Table 1) were admitted to hospital before our coronary care units were opened and were not referred to the cardiac unit. Table 1 shows that the mortality in the paced groups has fallen from 66 to $11 \%$, although the population of patients with poor prognosis, judged by anterior infarction, heartfailure and shock, was little different in the three groups. Factors responsible for the improvement in group $\mathrm{C}$ were thought to be early pacing with avoidance of syncope, impairment in cardiac output, demand-pacing with awareness of the possibility of inappropriate stimulation, and the free use of suppressant drugs.

\section{Early pacing}

In this series of eighty-two patients syncope was associated with a mortality of $52 \%$, compared with $20 \%$ in those without syncope (Table 2). Conclusions of the effect of syncope must be provisional because these patients are also the worst risk group, but early pacing to avoid syncope, and hence further deterioration in the clinical condition, seems to be a prime objective. Furthermore, the installation of a pacing system in a convulsing patient can be difficult.

\section{Cardiac output}

Improvement in the clinical state with pacing is often remarkable, but, if shock and heart failure continue, indicating a bad prognosis ( $43 \%$ mortality), atrioventricular pacing may improve cardiac output because of appropriate atrial systole (Martin \& Cobb, 1966).

TABLE 1. Mortality of acute myocardial infarction complicated by heart block

\begin{tabular}{lcccc}
\hline & $\begin{array}{c}\text { No. of } \\
\text { cases }\end{array}$ & $\begin{array}{c}\text { Death } \\
(\%)\end{array}$ & $\begin{array}{c}\text { Anterior } \\
\text { infarct. } \\
(\%)\end{array}$ & $\begin{array}{c}\text { Shock and } \\
\text { heart failure } \\
(\%)\end{array}$ \\
\hline $\begin{array}{l}\text { Unpaced: } \\
\text { 1963-66 }\end{array}$ & 32 & 71 & 38 & - \\
$\begin{array}{l}\text { Paced: } \\
\text { A. } 1961-66\end{array}$ & 18 & 56 & 27 & 66 \\
$\begin{array}{l}\text { Fixed rate pacing } \\
\text { B. } 1966-68\end{array}$ & 37 & 38 & 16 & 57 \\
$\begin{array}{l}\text { Demand pacing } \\
\text { C. } \begin{array}{l}\text { 1968-69 } \\
\text { Demand pacing and } \\
\text { suppressant therapy }\end{array}\end{array}$ & 27 & 11 & 22 & 66 \\
\hline
\end{tabular}


TABle 2. Prognostic factors in eighty-two patients with post-infarct atrioventricular block (second or third degree)

\begin{tabular}{lcc}
\hline & No. & $\begin{array}{c}\text { Mortality } \\
(\%)\end{array}$ \\
\hline Anterior infarct & $17(20 \%)$ & 76 \\
Inferior infarct & $65(80 \%)$ & 23 \\
Wide QRS & $26(31 \%)$ & 73 \\
Narrow QRS & $56(69 \%)$ & 16 \\
Onset known <24 hr after pain & $25(36 \%)$ & 32 \\
Onset known > 24 hr after pain & $45(64 \%)$ & 38 \\
Syncope & $34(42 \%)$ & 52 \\
No syncope & $48(58 \%)$ & 20 \\
Good clinical state & $22(26 \%)$ & 13 \\
Shock and failure & $60(73 \%)$ & 43 \\
Return to sinus rhythm & $60(73 \%)$ & 16 \\
No return to sinus rhythm & $22(27 \%)$ & 82 \\
\hline
\end{tabular}

\section{Demand pacing}

The fall in mortality with demand-pacing in 1966 coincided with a reduction of pacemaker power to just above threshold level, tested daily. The theoretical safety of demand pacing received a setback when inappropriate stimulation due to transient falls in the endocardial potential, used to inhibit the pacemaker, was found in some patients with shock (Fig. 6). It is possible that the death of some of the patients with shock who failed to improve with pacing could have been related to low cavity potentials and inappropriate stimulation producing ventricular dysrhythmias.

\section{Suppressant drugs}

The free use of suppressant drugs has been the major factor in reducing the high mortality associt ated with ectopic beats and ventricular dysrhythmias which may continue despite satisfactory pacing (Table 3). Increasing the pacing rate alone was on transiently effective in suppressing ectopic rhythros and intravenous lignocaine was far superior, though sometimes both were required.

The disadvantages of pacing are summarized Table 4. Electrode displacement would have less frequent if subclavian or external jugular veitis had been used for electrode insertion, but the aimter cubital vein approach is much easier for 50 nspecialized staff, particularly in a sick patient, a製s less worrying to the patient. There were four patier on demand pacemakers who were improving $\overline{\mathrm{e}} \mathrm{t}$ unexpectedly developed ventricular fibrillation agd

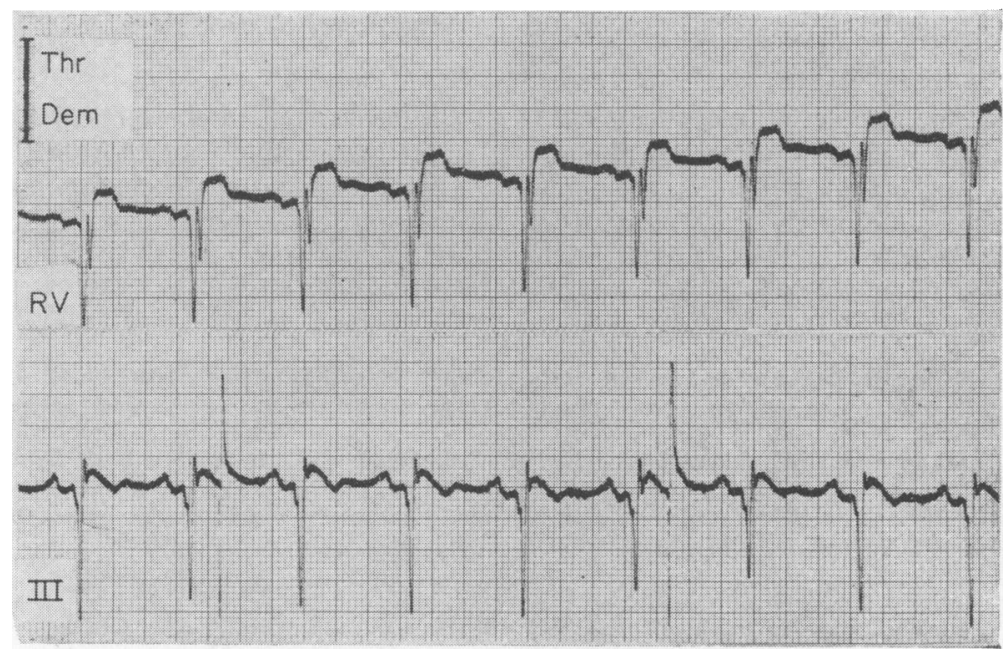

FIG. 6. The upper trace shows the RV endocardial potential which at times is too small to inhibit the demand pacemaker unit. The lower trace shows sinus rhythm and two inappiopriate pacemaker stimuli. $R V=$ right ventricle, III = lead III of the electrocardiogram, Thr Dem=minimum endocardial potential required to inhibit the demand pacemaker. 
TABLE 3. Deaths among thirty-nine patients $(47 \%$ of the eighty-two patients) with ventricular dysrhythmia not abolished by pacing

\begin{tabular}{lccc}
\hline & No. of & \multicolumn{2}{c}{ Deaths } \\
& patients & $($ No.) & $(\%)$ \\
\hline Suppressant drugs & 23 & 3 & 13 \\
No suppressant drugs & 16 & 11 & 68 \\
\hline
\end{tabular}

TABLE 4 Disadvantages of pacing in eighty-two patients

\begin{tabular}{lrc}
\hline & No. & Deaths \\
\hline VT or VF during electrode insertion & 6 & 0 \\
Electrode displacement & 19 & 0 \\
Suspected perforation (rise of threshold) & 3 & 0 \\
Phlebitis & 6 & 0 \\
Ectopic beats induced by pacing & 2 & 0 \\
Unexpected VF (demand) & 4 & 3 \\
Unexpected VF (fixed rate) & 1 & 1 \\
\hline
\end{tabular}

$\mathrm{VT}=$ ventricular tachycaldia, $\mathrm{VF}=$ ventricular fibrillation.

three died. Inappropriate stimulation without adequate ventricular suppressant therapy was probably a major factor.

Following a period of ventricular pacing the unpaced electrocardiogram shows massive $T$ wave inversion and ST depression which persists for a varying length of time depending on the duration of

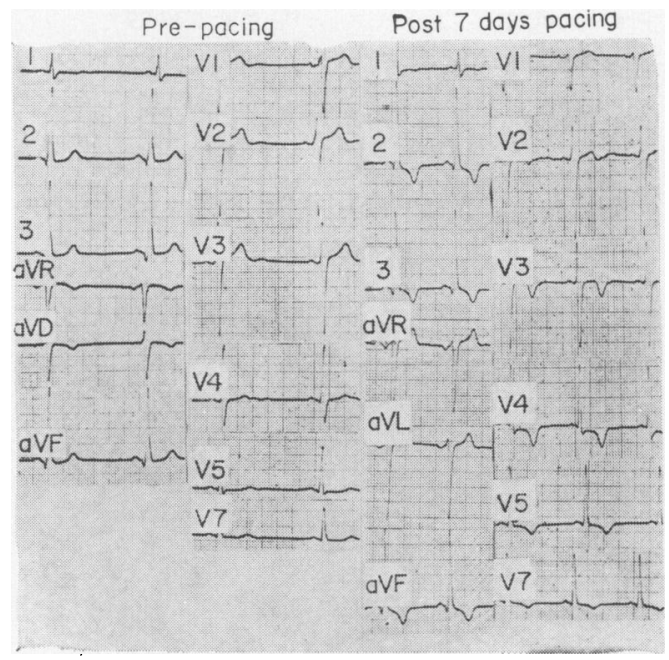

FIG. 7. The pre-paced electrocardiogram shows sinus rhythm with normal $S-T$ segments and $T$ waves. After 7 days of continuous ventricular pacing, an unpaced electrocardiogram shows conspicuous $T$ inversion in II, III, aVF, and $\mathrm{V}_{3}-\mathrm{V}_{7}$.

pacing (Figs 7 and 8). If the period of pacing is only a few minutes' duration (Fig. 9), then the ST and T wave changes rapidly regress, but if pacing has continued for several days, then the changes may persist for weeks. There is, however, nothing to suggest that the changes which occur in the ST segments and $T$ wave after depolarization from an

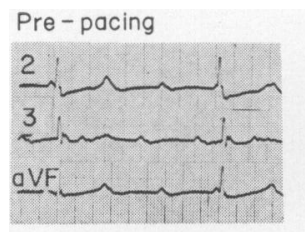

3 Days pacing

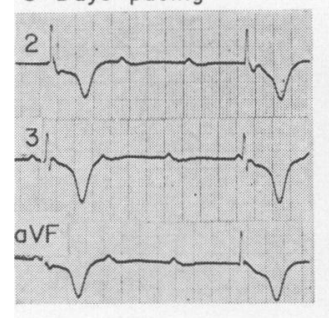

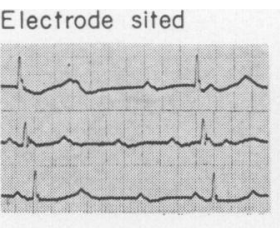

8 Days pacing

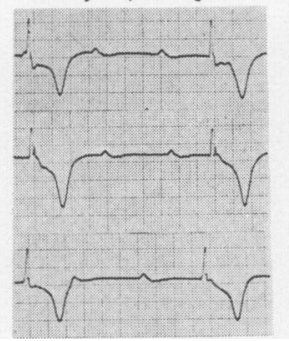

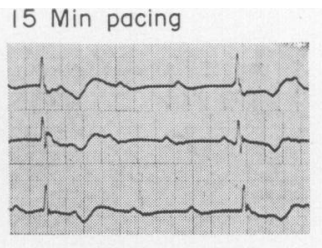

15 Days pacing

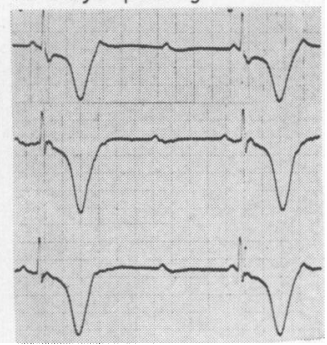

FIG. 8. Series of electrocardiograms obtained from the same patient during 15 days of endocardial pacing. The $T$ wave inversion progressively increased in II, III and aVF, reaching a maximum on day 15 . 


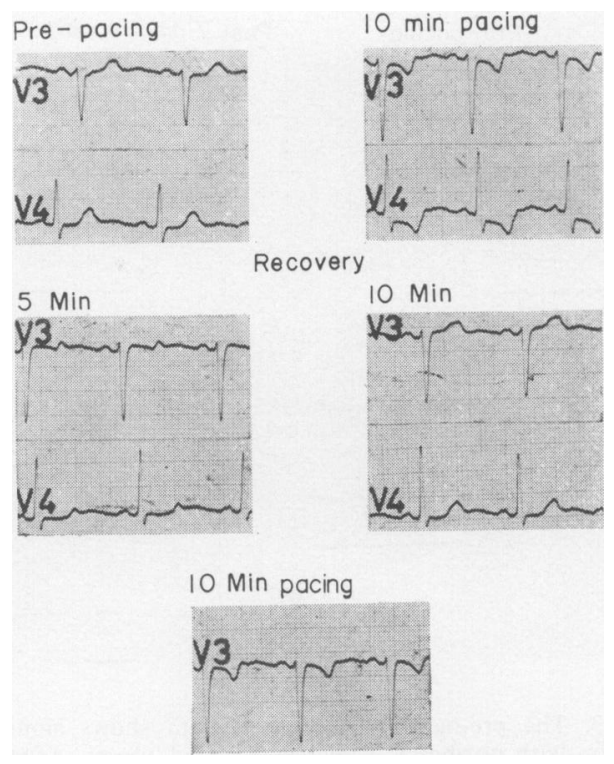

FIG. 9. A series of electrocardiograms obtained from the same patient pre-pacing and after short intervals of endocardial pacing. Immediately after $10 \mathrm{~min}$ of endocardial pacing $T$ inversion occurred in $V_{3}-V_{4}$ which fully regressed within $10 \mathrm{~min}$. A further $10 \mathrm{~min}$ of pacing produced $\mathrm{T}$ inversion again.

abnormal site are of any clinical importance, except that they may be misinterpreted as evidence of progressive coronary disease.

In conclusion, immediate low-power demand pacing for second and third degree block following infarction, together with the liberal use of myom cardial depressant drugs, appears to be lowering the mortality of this serious complication of myocardiait infarction. With the safeguards described, the dis? advantages of pacing are few and it is only when pacing system has been installed that it is safe to use suppressant drugs.

\section{References}

Brown, R.W., Hunt, D. \& Sloman, J.G. (1969) The natura history of atrioventricular conduction defects in acue myocardial infarction. American Heart Journal, 78, 460.

Epstein, E.J., Coulshed, N., McKendrick, C.S., Clark荺 J. \& KeARNS, W.E. (1966) Artificial pacing by electrołe catheter for heart block or asystole complicating acu myocaidial infarction. British Heart Journal, 28, 546.

Chatterjee, K., Harris, A., Leatham, A. \& Davies, G (1970) Fall on endocardial potentials after acute my@ir cardial infarction. Lancet, i, 1308.

Chatterjee, K., Sutton, R., Layton, C.A. \& Edwards, A. (1969) The cavity electrocardiogram in emergency arti ficial pacing. Postgraduate Medical Journal, 45, 713.

HARris, A. \& Bluestone, R. (1966) Treatment of slow heart rates following acute myocardial infarction. British Heaf Journal, 28, 631.

LASSERS, B.W. \& JULIAN, D.G. (1968) Artificial pacing management of complete heart block complicating aeute myocardial infarction. British Medical Journal, 2, $1420 \overrightarrow{0}$

MaRTIN, R.H. \& CoBB, L.A. (1966) Observations ondthed effect of atrial systole in man. Journal of Laboratory and Clinical Medicine, 68, 224.

Sutton, R., Chatterjee, K. \& Leatham, A. (1968) Heał block following acute myocardial infarction. Lancet, 645. 